\title{
Effects of dietary fat and carbohydrate on appetite vary depending upon site and structure
}

\author{
Stephen French* \\ Masterfoods (Division of Mars UK Ltd), Dundee Road, Slough, Berkshire SL1 4JX, UK
}

\begin{abstract}
The present review summarises the effects of different carbohydrate and fat structures on food intake and appetite and the differences in response at various levels of processing of macronutrients. Several physico-chemical properties of carbohydrate and fat molecules appear to influence the short-term satiating properties. However, long-term substantiation of these findings expressed in terms of food intake or body weight is not currently available. Such studies will be required to make clear recommendations regarding dietary composition to aid satiety.
\end{abstract}

Fat: Carbohydrate: Appetite

The physiological regulation of food intake and appetite involves a complex series of signals emanating from the gastrointestinal tract, liver and adipose stores, as well as centrally generated hunger and satiety signals. Given the epidemiological evidence that a high fat intake tends to lead to a higher body weight, a great deal of research has been conducted to investigate the relative effects of fat and carbohydrate on appetite and food intake. As the physiological processing systems involved in the ingestion, digestion, absorption and metabolism of foods are complex, it is not surprising that there are subtle differences associated with these macronutrients in terms of their subsequent satiating effects. The present review will attempt to summarise the effects of different carbohydrate and fat structures on food intake and appetite and the differences in response at various levels of processing of macronutrients.

\section{Oral preloading studies: fat $\boldsymbol{v}$. carbohydrate}

The standard methodology used in this area of research is that of oral preloading, whereby a covertly manipulated food or drink is given at a predetermined time before ingestion of an ad libitum test meal. Using this technique, the influence of fat and carbohydrate on subsequent intake have been widely tested. Many studies have indicated that fat is less satiating than carbohydrate and it has been thus suggested that fat may lead to passive over-consumption (Blundell et al. 1993). However, there have been a number of studies that do not support this contention, particularly when preloads have been matched for energy density and palatability (Geliebter, 1979). It appears that energy density is the key driver of satiety in these controlled conditions; there may be smaller individual effects of macronutrients and/or specific chemical differences that may provide useful insight into the regulation of intake and specific strategies that could be employed to manipulate satiety (Raben et al. 2003).

Many different carbohydrate molecules have been utilised in these studies: glucose; maltose; fructose; sucrose; maltodextrin. Similarly, a wide variety of oils and fats have been compared in this type of study (maize oil, Intralipid (commercially available lipid emulsion), SCFA, medium- and long-chain fatty acids, saturated and unsaturated fatty acids). Therefore, direct comparison between studies is difficult; however, it is clear that not all carbohydrates or fats act the same on appetite or the associated physiological processes. Some of the major classifications that can be taken from this wide literature follow.

\section{Carbohydrates}

Simple sugars

A wide variety of simple sugars have been utilised in tests of feeding behaviour. Ingested carbohydrates are digested and absorbed as simple monosaccharides or disaccharides and utilised or stored in the body as glucose (or polymers of glucose). Hence, the common monosaccharide molecules, glucose and fructose, have been widely used as sugar molecules in feeding behaviour studies. A large number of studies have demonstrated a compensatory response at an ad libitum feeding test to ingestion of a preload of monosaccharides or disaccharides when compared with a non-nutritive sweetened control drink or added to a test food (Rogers et al. 1988; Lavin et al. 
1997). It should be noted, however, that not all studies have demonstrated a compensation for sugar ingestion and in some cases a stimulation of intake has been observed (e.g. Spitzer \& Rodin, 1987). As will be discussed, considering the wide differences in physiological response and methodological differences employed (for review of methodologies, see Reid \& Hetherington, 1997), it is not surprising that differences in feeding effect are found.

\section{Glucose v. fructose}

Glucose and fructose are the two major monosaccharides and principal components of available sugars; thus, the comparison of glucose and fructose has been of wide interest in terms of appetite regulation and subsequent physiological responses. This area is becoming increasingly of interest as some studies have suggested that increased fructose consumption may be associated with weight gain. Contrary to this argument, however, a number of studies have shown that fructose reduces appetite and food intake to a greater extent than glucose (Spitzer \& Rodin, 1987; Rayner et al. 2000). One study, however, has shown no difference in appetite or food intake between fructose and glucose (Kong et al. 1999).

Gastric emptying rate of fructose is more rapid than glucose (Guss et al. 1994) and insulin release is lower following fructose ingestion in human subjects (MacDonald et al. 1978). These differences are probably related to the specific intestinal transporter mechanisms for fructose and glucose (Levin, 1994). The response to glucose and fructose seems to depend upon site of administration, as Kong et al. (1999) showed that oral fructose was less effective in stimulating the putative satiety hormone, glucagon-like peptide-1, whilst having similar effects on appetite and subsequent food intake. Rayner et al. (2000) demonstrated, on the other hand, that intraduodenal infusion of fructose reduces subsequent food intake to a greater extent than glucose, whilst having a similar stimulatory effect on glucagon-like peptide-1. These differences are difficult to explain purely in terms of gastric delivery differences in the oral condition, as it would be expected that fructose would empty more quickly and may reduce appetite (at least in the short term) more strongly than glucose and raise glucagon-like peptide-1 concentrations more strongly.

The faster gastric emptying and lower insulin response of fructose are also observed when it is incorporated into the disaccharide sucrose (glucose-fructose) when compared with maltose (glucose-glucose). Despite the differences in gastric emptying, appetite responses to sucrose and maltose have been shown to be similar (Lavin et al. 2002).

\section{Polysaccharides}

The major current area of interest concerning the role of polysaccharides and satiety relates to the glycaemic index (GI) of carbohydrate-containing products. GI relates to the speed at which a fixed amount (usually 75 or $50 \mathrm{~g}$ ) of ingested carbohydrate source raises blood glucose over a fixed time period ( 2 or $3 \mathrm{~h}$ ), expressed as a percentage of a reference blood glucose response (to glucose or white bread consumption; Jenkins et al. 1981). A great deal of work has been carried out to investigate the relationship between blood glucose or its utilisation and hunger and food intake (Campfield, 1997; Melanson et al. 1999). Hence, as the use of GI has become more widespread, its role in determining the satiety response has been investigated. There is still a great deal of controversy on the long-term influence of a low-GI diet on body weight and there is a general call for randomised, controlled intervention trials in this area. However, several shortterm studies have been conducted that have investigated the role of the GI of test foods on subsequent appetite and food intake. In a recent review (Raben, 2002) of thirty-one short-term studies, fifteen studies demonstrated that low-GI foods reduce hunger or increase satiety, fourteen found no effect and two actually found lower satiety following the low-GI test compared with the high-GI test. As with many areas of research, a wide variety of methodologies have been employed, making a systematic analysis of the key factors potentially accounting for differences difficult. Certainly, the physiological profile of low-GI diets (slower gastric emptying, digestion and absorption, lower peak insulin and glucose followed by slower declines and less severe nadirs in glucose levels) would fit with scientific knowledge concerning appetite suppression (Pawlak et al. 2002). Further well-controlled, appropriately powered, randomised intervention trials are needed to critically address this question (Astrup, 2002).

\section{Fats}

Three major areas associated with fat structure have been investigated with regard to their satiating effectiveness. Chain length and degree of saturation of fats have a large impact on their physico-chemical properties and several studies have investigated the role of these factors on appetite and eating behaviour. The final area that has received some attention relates to the functionality of specific fat molecules, particularly conjugated linoleic acid (CLA), mainly in terms of weight regulation and metabolism, but also recently on food intake and appetite.

\section{Chain length}

Medium-chain triacylglycerols (MCT) are hydrolysed and absorbed more rapidly than long-chain triacylglycerols. MCT are hydrolysed to medium-chain fatty acids, which are directly absorbed into the portal system, whereas long-chain triacylglycerols are transported in chylomicrons and through the lymphatic system. In addition, MCT are preferentially oxidised and are able to cross the inner mitochondrial membrane independently of acylcarnitine transferase (Bremer, 1983); increases in fatty acid oxidation in the liver has itself been proposed as a satiety signal (Langhans, 1996).

A number of studies have shown MCT to be more satiating than long-chain triacylglycerols in both animals and 
human subjects (Stubbs \& Harbron 1996; Wymelbeke et al. 1998). Furthermore, MCT added to a very-low energy diet have been shown to speed the rate of weight loss and enhance satiety in the first 2 weeks of weight loss (Krotkiewski, 2001). Within the range of MCT, it has previously been demonstrated that longer-chain-length molecules lead to a greater inhibition of food intake in rats (McCaffery et al. 1994). Chain length of fatty acids also appears critical for cholecystokinin release with a cut-off point of $\mathrm{C}_{12}$, below which there appears to be no release (McLaughlin et al. 1999).

\section{Saturation}

The influence of the degree of saturation of the fatty acid molecules (either as salts of the fatty acids or as oils/emulsions) upon appetite and food intake has been tested in both animals and more recently in human subjects. The degree of saturation influences a number of the physico-chemical properties of the oil (e.g. melting point) as well as the rate of digestion and absorption (Small, 1991).

Within the $\mathrm{C}_{18}$ fatty acids, linoleic acid was found to be more satiating when infused into the upper small intestine in human subjects than oleic or stearic acids (French et al. 2000). Similar findings have been noted when oils are incorporated into foods (Lawton et al. 2000). These findings may relate to the speed of processing of the different oils and possibly to the neurochemical responses evoked following ingestion. Cholecystokinin has previously been shown to be more potently released following linoleic acid-containing oils compared with other longchain fatty acid-containing oils (Beardshall et al. 1989). ApoA-IV release is also more potently released by linoleic acid in rats (Kalogeris et al. 1996). Both of these gastrointestinal chemicals have been shown to induce satiety (Fujimoto et al. 1992; Ballinger et al. 1995).

\section{Conjugated linoleic acid}

CLA has recently been implicated with a number of potential health benefits. Several studies have recently been carried out in human subjects to investigate the effects of CLA supplementation on measures of obesity. These studies have shown that daily intake of CLA can reduce total body fat (Blankson et al. 2000) or abdominal fat (Riserus et al. 2001). In addition, two studies have also shown significant reductions (Medina et al. 2000) or inverse associations (Belury et al. 2003) with circulating leptin levels. Of these studies, however, only one has attempted to assess appetite effects of CLA in human subjects without significant findings (Medina et al. 2000).

\section{Summary}

Several physico-chemical properties of carbohydrate and fat molecules appear to influence the short-term satiating properties. However, long-term substantiation of these findings expressed either in terms of food intake or body weight is not currently available. Such studies will be required to make clear recommendations regarding dietary composition to aid satiety.

\section{References}

Astrup A (2002) The role of the glycaemic index of foods in body weight regulation and obesity. Is more evidence needed? (Editorial). Obes Rev 3, 233.

Ballinger A, McLoughlin L, Medbak S \& Clark M (1995) Cholecystokinin is a satiety hormone at physiological post-prandial plasma concentrations. Clin Sci 89, 375-381.

Beardshall K, Frost G, Morarji Y, Domin J, Bloom SR \& Calam J (1989) Saturation of fat and CCK release: implications for pancreatic carcinogenesis. Lancet ii, 1008-1010.

Belury MA, Mahon A \& Banni S (2003) The conjugated linoleic acid (CLA) isomer, t10c12-CLA, is inversely associated with changes in body weight and serum leptin in subjects with type 2 diabetes mellitus. $J$ Nutr 133, 257S-260S.

Blankson H, Stakkestad JA, Fagertun H, Thom E, Wadstein J \& Gudmundsen O (2000) Conjugated linoleic acid reduces body fat mass in overweight and obese humans. J Nutr 130, $2943-2948$.

Blundell JE, Burley VJ, Cotton JR \& Lawton CL (1993) Dietary fat and the control of energy intake: evaluating the effects of fat on meal size and postmeal satiety. Am J Clin Nutr 57, Suppl., $772 \mathrm{~S}-777 \mathrm{~S}$

Bremer J (1983) Carnitine - metabolism and functions. Physiol Rev 63, 1420-1479.

Campfield LA (1997) Metabolic and hormonal controls of food intake: highlights of the last 25 years $-1972-97$. Appetite 29, 135-152.

French SJ, Conlon CA, Mutuma ST, Arnold M, Read NW, Meijer G \& Francis J (2000) The effects of intestinal infusion of fatty acids on food intake in man. Gastroenterology 119, 943-948.

Fujimoto K, Cardelli JA \& Tso P (1992) Increased apolipoprotein A-IV in rat mesenteric lymph after meals acts as a physiological signal for satiation. Am J Physiol 262, G1002-G1006.

Geliebter AA (1979) Effects of equicaloric loads of protein, fat, and carbohydrate on food intake in the rat and man. Physiol Behav 22, 267-273.

Guss JL, Kissileff HR \& Pi-Sunyer FX (1994) Effects of glucose and fructose solutions on food intake and gastric emptying in nonobese women. Am J Physiol 267, R1537-R1544.

Jenkins DJ, Wolever TM, Taylor RH, Barker H, Fielden H, Baldwin JM, Bowling AC, Newman HC, Jenkins AL \& Goff DV (1981) Glycemic index of foods: a physiological basis for carbohydrate exchange. Am J Clin Nutr 34, 362-366.

Kalogeris TJ, Monroe F, Demichele SJ \& Tso P (1996) Intestinal synthesis and lymphatic secretion of apolipoprotein A-IV vary with chain length of intestinally infused fatty acids in rats. $J$ Nutr 126, 2720-2729.

Kong MF, Chapman I, Goble E, Wishart J, Wittert G, Morris H \& Horowitz M (1999) Effects of oral fructose and glucose on plasma GLP-1 and appetite in normal subjects. Peptides 20, 545-551.

Krotkiewski M (2001) Value of VLCD supplementation with medium chain triglycerides. Int J Obes 25, 1393-1400.

Langhans W (1996) Metabolic and glucostatic control of feeding. Proc Nutr Soc 55, 497-515.

Lavin JH, French SJ \& Read NW (1997) The effect of sucroseand aspartame-sweetened drinks on energy intake, hunger and food choice of female, moderately restrained eaters. Int $J$ Obes 21, 37-42.

Lavin JH, French SJ \& Read NW (2002) Comparison of oral and gastric administration of sucrose and maltose on gastric emptying rate and appetite. Int J Obes 26, 80-86.

Lawton CL, Delargy HJ, Brockman J, Smith FC \& Blundell JE (2000) The degree of saturation of fatty acids influences post-ingestive satiety. Br J Nutr $\mathbf{8 3}, 473-482$. 
Levin RJ (1994) Digestion and absorption of carbohydrates from molecules and membranes to humans. Am J Clin Nutr 59, Suppl., 690S-698S.

McCaffery J, French SJ \& Greenberg D (1994) Differential satiety effects after duodenal infusion of medium-chain fatty acids in sham feeding rats. Appetite 23, 315 Abstr.

Macdonald I, Keyser A \& Pacy D (1978) Some effects, in man, of varying the load of glucose, sucrose, fructose, or sorbitol on various metabolites in blood. Am J Clin Nutr 31, 1305-1311.

McLaughlin J, Grazia Luca M, Jones MN, D’Amato M, Dockray GJ \& Thompson DG (1999) Fatty acid chain length determines cholecystokinin secretion and effect on human gastric motility. Gastroenterology 116, 46-53.

Medina EA, Horn WF, Keim NL, Havel PJ, Benito P, Kelley DS, Nelson GJ \& Erickson KL (2000) Conjugated linoleic acid supplementation in humans: effects on circulating leptin concentrations and appetite. Lipids 35, 783-788.

Melanson KJ, Westerterp-Plantenga MS, Saris WHM, Smith FJ \& Campfield LA (1999) Blood glucose patterns and appetite in time-blinded humans: carbohydrate versus fat. Am J Physiol 277, R337-R345.

Pawlak DB, Ebbeling CB \& Ludwig DS (2002) Should obese patients be counselled to follow a low-glycaemic index diet? Yes. Obes Rev 3, 235-243.

Raben A (2002) Should obese patients be counselled to follow a low-glycaemic index diet? No. Obes Rev 3, 245-256.

Raben A, Agerholm-Larsen L, Flint A, Holst JJ \& Astrup A (2003) Meals with similar energy densities but rich in protein, fat, carbohydrate, or alcohol have different effects on energy expenditure and substrate metabolism but not on appetite and energy intake. Am J Clin Nutr 77, 91-100.

Rayner CK, Park HS, Wishart JM, Kong M, Doran SM \& Horowitz M (2000) Effects of intraduodenal glucose and fructose on antropyloric motility and appetite in healthy humans. Am J Physiol 278, R360-R366.

Reid M \& Hetherington M (1997) Relative effects of carbohydrates and protein on satiety - a review of methodology. Neurosci Biobehav Rev 21, 295-308.

Riserus U, Berglund L \& Vessby B (2001) Conjugated linoleic acid (CLA) reduced abdominal adipose tissue in obese middle-aged men with signs of the metabolic syndrome: a randomised controlled trial. Int J Obes 25, 1129-1135.

Rogers PJ, Carlyle J, Hill AJ \& Blundell JE (1988) Uncoupling sweet taste and calories: comparison of the effects of glucose and three intense sweeteners on hunger and food intake. Physiol Behav 43, 547-552.

Small DM (1991) The effect of glyceride structure on absorption and metabolism. Annu Rev Nutr 11, 413-434.

Spitzer L \& Rodin J (1987) Effects of fructose and glucose preloads on subsequent food intake. Appetite 8, 135-145.

Stubbs RJ \& Harbron CG (1996) Covert manipulation of the ratio of medium- to long-chain triglycerides in isoenergetically dense diet: effect on food intake in ad libitum feeding men. Int J Obes 20, 435-444.

Wymelbeke V van, Himaya A, Louis-Sylvestre J \& Fantino M (1998) Influence of dietary medium-chain and long-chain triacylglycerols on the control of food intake in men. Am J Clin Nutr 68, 226-234. 